\title{
Inflammatory etiopathogenesis of systemic lupus erythematosus: an update
}

\author{
This article was published in the following Dove Press journal: \\ Journal of Inflammation Research \\ 20 August 2015 \\ Number of times this article has been viewed
}

\section{Malgorzata J Podolska \\ Mona HC Biermann \\ Christian Maueröder \\ Jonas Hahn \\ Martin Herrmann}

Department of Internal Medicine 3, Institute for Clinical Immunology and Rheumatology, Friedrich-Alexander University of Erlangen-Nuremberg, Erlangen, Germany
Correspondence: Martin Herrmann Department of Internal Medicine 3, Institute for Clinical Immunology and Rheumatology, Friedrich-Alexander University of Erlangen-Nürnberg, Ulmenweg 18, 91054 Erlangen, Germany $\mathrm{Tel}+499$ 9। 318536990

Fax +4991318535776

Email martin.herrmann@uk-erlangen.de
Abstract: The immune system struggles every day between responding to foreign antigens and tolerating self-antigens to delicately maintain tissue homeostasis. If self-tolerance is broken, the development of autoimmunity can be the consequence, as it is in the case of the chronic inflammatory autoimmune disease systemic lupus erythematosus (SLE). SLE is considered to be a multifactorial disease comprising various processes and cell types that act abnormally and in a harmful way. Oxidative stress, infections, or, in general, tissue injury are accompanied by massive cellular demise. Several processes such as apoptosis, necrosis, or NETosis (formation of Neutrophil Extracellular Traps [NETs]) may occur alone or in combination. If clearance of dead cells is insufficient, cellular debris may accumulate and trigger inflammation and leakage of cytoplasmic and nuclear autoantigens like ribonucleoproteins, DNA, or histones. Inadequate removal of cellular remnants in the germinal centers of secondary lymphoid organs may result in the presentation of autoantigens by follicular dendritic cells to autoreactive B cells that had been generated by chance during the process of somatic hypermutation (loss of peripheral tolerance). The improper exposure of nuclear autoantigens in this delicate location is consequently prone to break self-tolerance to nuclear autoantigens. Indeed, the germline variants of autoantibodies often do not show autoreactivity. The subsequent production of autoantibodies plays a critical role in the development of the complex immunological disorder fostering SLE. Immune complexes composed of cell-derived autoantigens and autoantibodies are formed and get deposited in various tissues, such as the kidney, leading to severe organ damage. Alternatively, they may also be formed in situ by binding to planted antigens of circulating autoantibodies. Here, we review current knowledge about the etiopathogenesis of SLE including the involvement of different types of cell death, serving as the potential source of autoantigens, and impaired clearance of cell remnants, causing accumulation of cellular debris.

Keywords: apoptosis, NETosis, cell death, clearance deficiency, autoimmunity, systemic lupus erythematosus

\section{Introduction}

Under physiological conditions, the efficient removal of dead cells and their remnants prevents the accumulation of cellular debris that may serve as a potential source of autoantigens. Abnormal cell demise and impaired or delayed clearance of cellular remnants are considered to play a crucial role in the etiology of autoimmune diseases such as systemic lupus erythematosus (SLE) ${ }^{1,2}$ It is thought that both environmental factors, such as chemicals, drugs, or pathogens, and genetic predisposition, shown by genomewide association studies, contribute to the development of this disease. ${ }^{3-5}$ The progression of the malady is fostered by the formation of immune complexes leading to a plethora of clinical manifestations, such as butterfly rash, nephritis, glomerulonephritis, 
proteinuria, seizures, arthritis, thrombocytopenia, serositis, and psychosis. SLE affects women (before menopause) nine times more often than men. ${ }^{6}$ Among the many types of cell death, "suicidal" apoptosis, "passive" necrosis, and neutrophil extracellular trap formation (NETosis) are supposed to be the source of autoantigens that play an important role in the etiology and pathogenesis of SLE. ${ }^{7-9}$ Insufficient clearance of post-apoptotic cells is an intrinsic and complex defect embracing several entities from defective phagocytosis to erroneous opsonization of autoantigens by autoreactive immunoglobulin $\mathrm{G}$ (IgG). This shifts their engulfment to an inflammatory pathway. Among others, poorly functioning phagocytic cells ("lazy macrophages") and deficiencies of DNase I or C1q mainly contribute to the hampered clearance of dying cells. ${ }^{10,11}$ In addition, a failure along the pathway from apoptotic cell recognition to TLR9 signaling may be involved in the development of autoimmunity. ${ }^{12}$ This review discusses how a failure in the above-mentioned mechanisms and their key players contributes to the development and maintenance of SLE.

\section{Apoptosis}

Apoptosis is a highly controlled and well-organized process involved in many physiological conditions, such as embryogenesis and normal tissue turnover. The intentional suicide of cells which are no longer required, as is the case with immune cells after resolution of infection or cells whose DNA is damaged, is mandatory for the preservation of tissue homeostasis and prevention of malignancies. During the execution of this form of cell demise, the integrity of the cell membrane is maintained as long as possible, avoiding autoantigen leakage and triggering of immune responses. ${ }^{13-16}$

Apoptosis can be initiated either intrinsically (mitochondrial) or extrinsically (death receptor-mediated). In both pathways, effector caspases are proteolytically activated. They cleave a plethora of intracellular substrates such as focal adhesion or cytoskeleton proteins, consequently leading to weakening of the plasma membrane scaffold. Moreover, molecules such as DNA fragmentation factor ${ }^{17}$ and caspaseactivated deoxyribonuclease are activated. ${ }^{18}$ Simultaneous inactivation of poly(ADP-ribose) polymerase consequently results in the degradation of the DNA. ${ }^{19,20}$ The action of the effector caspases contributes to the characteristic phenotype of an apoptotic cell.

The cell executes a series of morphological and biochemical changes comprising chromatin condensation, fragmentation of the nucleus, blebbing, cell shrinkage, and formation of apoptotic bodies. The latter contain modified cell-derived material. ${ }^{21,22}$
The content of these membranous particles presents a potential source of (often) nuclear autoantigens, which are typically recognized by autoantibodies in patients with SLE. ${ }^{23}$

\section{Signals during apoptosis}

When a cell undergoes apoptosis in vivo, it has to be recognized, ingested, and rapidly degraded in an immunologically silent manner. Thus, an apoptotic cell exposes and secretes a series of signals in order to ensure its quick and efficient engulfment (Table 1). Exposing "find me" signals, the apoptotic cell attracts professional and non-professional phagocytes, ${ }^{24}$ which are able to engulf the dying cell in the presence of "eat me" signals, like phosphatidylserine (PS) ${ }^{25,26}$ In living cells, PS is mainly restricted to the inner leaflet of the plasma membrane. ${ }^{27}$ During apoptosis, this asymmetrical distribution is lost. ${ }^{28}$ In some cells, such as resting $\mathrm{B}$ cells. ${ }^{29}$ or activated $\mathrm{CD} 8^{+} \mathrm{T}$ cells, ${ }^{30} \mathrm{PS}$ transiently appears on the cells' surfaces. In these cases, PS exposure does not initiate engulfment by phagocytes. Thus, surface exposure of PS is not sufficient for serving as an "eat me" signal. ${ }^{31}$ During apoptosis, when the cytoskeleton is fragmented by proteolytic cleavage, the high lateral mobility of its components is discussed to precipitate an adequate recognition and phagocytosis. ${ }^{32,33}$ On the one hand, recognition of apoptotic cells is directly mediated by receptors on the surfaces of phagocytes, such as Bal-1, ${ }^{34}$ stabilin-2, ${ }^{35}$ Tim-1, and Tim- $4 .^{36,37}$ On the other hand, efferocytosis is facilitated indirectly by the soluble bridging molecules, such as CRP, annexin A1, $\beta 2$ GPI, MFG-E8, and Gas-6, and their receptors on phagocytes. The bridging enables a close positioning of the phagocyte and its prey. ${ }^{32-34,37,38}$ The activation of an intracellular signaling cascade finally results in the remodeling of the actin cytoskeleton and the ingestion of the apoptotic corpse. ${ }^{39}$ "Stay away" signals, such as lactoferrin, are secreted by the apoptotic cell to prevent granulocyte attraction, inflammation, and the triggering of an immune response. Consequently, the migration of neutrophils to the site of apoptosis is inhib-

Table I Signals and signaling molecules released during apoptosis and phagocytosis

\begin{tabular}{ll}
\hline Signal & Signaling molecules \\
\hline "Find me" & Fractalkine (CX3CLI) \\
& Sphingosine-I-phosphate (SIP) \\
& Adenosine triphosphate (ATP) \\
& Lysophosphatidylcholine (LPC) \\
"Eat me" & Phosphatidylserine (PS) \\
"Stay away" & Lactoferrin (LF) \\
"Tolerate me" & Transforming growth factor beta (TGF- $\beta$ ) \\
& Interleukin I0 (IL-I0) \\
\hline
\end{tabular}


ited. ${ }^{40}$ The uptake of cellular debris causes the secretion of the anti-inflammatory cytokine interleukin 10 (IL-10) by phagocytes, often referred to as a "tolerate me" signal. ${ }^{25}$ The production of the proinflammatory cytokines, such as tumor necrosis factor alpha (TNF- $\alpha$ ), IL-1, or IL-12, by phagocytes is decreased during ingestion. Finally, the highly regulated process of cell death allows the clearance of dying cells without triggering inflammatory responses and represents a hallmark of apoptosis. ${ }^{33}$

\section{Failure of dead cell clearance leads to secondary necrosis and SLE}

As mentioned earlier, immunological silence during apoptotic cell death is achieved by maintaining the integrity of the cellular membrane and the subsequent secretion of antiinflammatory cytokines by engulfing phagocytes. The fast and efficient removal of dying cells and their remnants prevents progression of apoptotic cells to the stage of secondary necrosis, accompanied by rupture of the cell membrane and subsequent release of harmful intracellular contents including the damage-associated molecular pattern molecules, HMGB1, ATP, uric acid, and hyaluronic acid. Hampered removal of cells undergoing apoptosis may lead to the induction of inflammation and autoimmune responses. ${ }^{41-44}$ The production of autoantibodies and the consecutive opsonization of intracellular autoantigens by those antibodies foster the uptake of secondary necrotic cell-derived material by phagocytes. The secretion of the pro-inflammatory cytokines such as IL-8, interferon alpha (IFN- $\alpha$ ), TNF- $\beta$, IL-18, and IL-1 $\beta$ fuels inflammation and promotes further tissue damage. ${ }^{45}$ As a consequence, circulating immune complexes are formed and may bind to tissues or deposit, inter alia, in the skin, joints, or kidneys. ${ }^{46}$ This leads to the activation of the complement system that attracts innate immune cells promoting local inflammation. The activation of plasmacytoid dendritic cells (pDC) by immune complexes results in the secretion of IFN- $\alpha$, establishing the so-called "IFN- $\alpha$ signature" of leukocytes. As a result of the deposition of the immune complexes and activation of inflammatory processes, severe organ damage occurs, which in turn fuels the vicious cycle of accumulation of secondary necrotic cells and inflammatory clearance driving SLE. The established inflammatory processes encompass both a persistent immunostimulatory status and several rather short-lasting recurrent flares.

In the course of SLE, the canonically immune silent pathway of apoptosis turns into a harmful source of autoantigens and immunostimulatory signals prone to sustain chronic autoimmune responses. Importantly, also in healthy individuals, a few apoptotic cells can undergo secondary necrosis, but fast degradation and removal with the participation of DNase I and C1q ensures the maintenance of immune tolerance. ${ }^{47-49}$

\section{Primary necrosis in the development of SLE}

Necrosis is provoked by exogenous factors that damage the cell, such as toxic events or mechanical injury. As a consequence, swelling of the oncotic cell causes sudden rupture of the membrane. This leads to cellular leakage of modified and deleterious intracellular material into the extracellular space. Neutrophils, lymphocytes, and macrophages migrate to the site of efflux of intracellular content and initiate inflammation. ${ }^{50,51}$ Thus, tissue damage may contribute to the development of the autoimmune disease SLE. Overwhelming cell death combined with a defective clearance of dying and dead cells is associated with the break of self-tolerance.

\section{The role of NETosis in the development of SLE}

Neutrophils are the most abundant granulocytes that play a crucial role in the defense against microbial infections. Attracted by tissue-resident macrophages, resident mast cells, or endothelial cells, they migrate from the blood vessels to the site of injury, where they engulf pathogens, degranulate by releasing antimicrobial molecules, and secrete proinflammatory cytokines. ${ }^{52}$ Neutrophils are able to attract DC by the secretion of $\mathrm{C}-\mathrm{C}$ chemokines, like MIP-3 $\alpha / \mathrm{CCL} 20$ and MIP-3 $\beta /$ CCL19. ${ }^{53}$ Under healthy conditions, neutrophils undergo apoptosis and are engulfed and cleared by tissueresident macrophages. ${ }^{54}$

At the site of infection, neutrophils are able to form neutrophil extracellular traps (NETs) decorated with several antimicrobial molecules. This form of suicidal cell death is referred to as NETosis. ${ }^{55}$ NETs consist of processed chromatin associated with cytoplasmic proteins and granules. The latter are vesicles containing toxic, microbicidal molecules. These granules associate with the NETs during the process of NETosis. Four types of granules can be distinguished: azurophilic (primary) granules, specific (secondary) granules, gelatinase (tertiary) granules, and secretory vesicles. NETosis also occurs in response to invading pathogens and exogenous or endogenous stimuli, like fine dust or monosodium urate crystals. NETosis can also be induced by the proinflammatory cytokines IL- 8 and IL- $1 \beta$ or platelet activation factor. Eosinophils and basophils are also able to externalize their chromatin and form extracellular DNA-based traps. ${ }^{56}$ 
The formation of NETs involves several steps. First, activated neutrophils get in contact with the stimulus and disintegration of granules occurs. Neutrophil elastase and myeloperoxidase, which are released from azurophilic granules, reach the cellular nucleus orchestrating histone modification and chromatin decondensation. ${ }^{57,58}$ Another important modification of histones is peptidylarginine deiminase 4 (PAD4)-mediated citrullination. This enzyme is a member of the PAD family, which consists of five isotypes. Only PAD4 possesses a nuclear localization signal. ${ }^{59-61}$ Citrullination of histone $\mathrm{H} 3$ plays an important role in the decondensation of the chromatin during NETosis. As a result, the nuclear envelope is destroyed and the integrity of cell membrane is lost. This leads to the rapid release of DNA-containing net-like structures. ${ }^{62}$ Neutrophil elastase is able to partially degrade the linker and core histones, thus creating neoantigens. Moreover, histones can undergo other relevant modifications such as acetylation, methylation, hyperubiquitination, or poly(ADP-ribosyl)ation, possibly determining their immunogenic capacities. ${ }^{63}$ Besides their important function as a scaffold for nucleosome formation, the basic histone proteins can also kill pathogens. ${ }^{64}$

As mentioned earlier, several patients suffering from SLE are seropositive for antibodies that recognize cytoplasmic autoantigens from neutrophils. These autoantibodies recognize components of NETs like neutrophil elastase, myeloperoxidase, LL-37, or lactoferrin. ${ }^{65}$ In addition, these autoantibodies promote IFN- $\alpha$ production by $\mathrm{pDC}$ and thus contribute to the IFN- $\alpha$ signature. Autoantibodies specific for surface-expressed LL-37 induce the release of NETs by neutrophils. Enhanced LL-37 surface expression in turn fuels inflammation and autoantibody production via IFN- $\alpha \cdot{ }^{66,67}$ Furthermore, NETosis is accompanied by the release of noxious intracellular constituents such as heat shock proteins, modified histones, or HMGB1. These intracellular proteins are able to activate DC and may thus challenge immune tolerance. ${ }^{68}$ Since NETs are composed of DNA, they are prone to degradation by DNase I. In the case of patients with SLE, this nuclease may act insufficiently as a result of inhibitors, anti-DNase I antibodies, or genetic variations. ${ }^{69}$ This may cause persistence of NETs serving as a source for potential autoantigens, thereby challenging self-tolerance (Figure 1). Importantly, a neutrophil subpopulation enriched in the blood of patients suffering from SLE is more prone to execute NETosis. ${ }^{66,67}$ It has recently been shown that neutrophils isolated from patients with SLE reveal a robust pattern of demethylation of the IFN-regulated genes, suggesting a pathogenic role for neutrophils in lupus. ${ }^{70}$

Neutrophils may secrete proinflammatory cytokines and factors able to activate B cells such as a proliferation-inducing ligand, if activated by deposited immune complexes. Nevertheless, aggregated NETs are also important to confine and resolve inflammation. They are able to trap pro-inflammatory cytokines and chemokines, which are consequently proteolytically degraded. This limits the inflammatory response. ${ }^{71}$

\section{Implications of impaired phagocytosis on autoimmunity}

Hampered clearance of cellular debris is discussed to play a substantial role in the development of SLE. It is, among others, the result of failures in the processes of apoptosis and/or phagocytosis. In healthy individuals, cellular debris is cleared in a fast and efficient manner. Signals released by apoptotic cells during their death induce attraction of phagocytes, which engulf and digest cellular remnants before the integrity of the cellular membrane is lost. This prevents the triggering of an inflammatory reaction.

Opsonization facilitates the proper removal of cell remnants. Under healthy conditions, the recognition of dead cells is supported by opsonins like IgM, the complement component C1q, CRP, or MBP. Several patients with SLE reportedly show decreased levels of these components in their sera. In individuals who are genetically predisposed to develop SLE, decreased levels of MBP and C1q have been shown to be associated with the disease. ${ }^{72,73}$ A cooperation of C1q and DNase I accelerates the degradation of necrotic cells-derived chromatin. ${ }^{49,74}$ The combination of a failure in the effective and immunologically silent opsonization of dead cell remnants and the abnormal immunogenic opsonization by autoantibodies of secondary necrotic cellderived materials substantially contributes to the development of autoimmune disease and fuels chronic inflammation. This highlights the important role of opsonization of dead and dying cells for the multifactorial and complex disorder SLE.

A reduction in the phagocytic capacity and impaired adhesion is a hallmark of monocyte-derived macrophages (MDM) found in patients with SLE. Professional phagocytes and antigen-presenting cells of patients with SLE show a decreased size and capacity to engulf their prey, when compared with cells isolated from the blood of normal healthy donors. ${ }^{75}$ Additionally, MDMs isolated from patients suffering from SLE exhibit a decreased adhesion ${ }^{76}$ and an impaired production of the adhesion molecule CD44, which also contributes to the clearance of apoptotic neutrophils. ${ }^{77}$ Consequently, the removal of their apoptotic remnants by MDMs is impaired. There is also evidence that MDMs isolated from patients with SLE die faster than those isolated from normal healthy donors. ${ }^{78}$ 


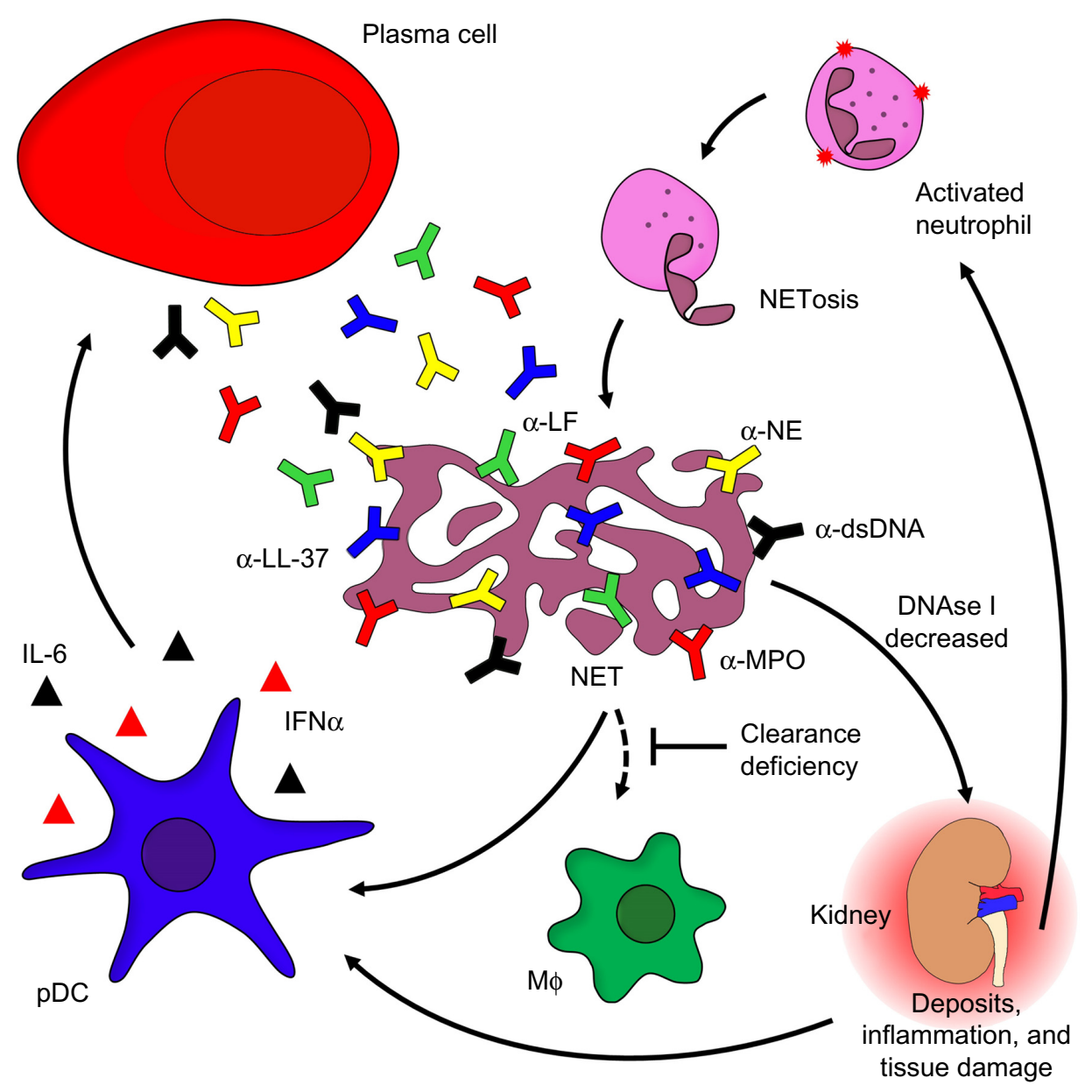

Figure I The role of neutrophils in the etiopathogenesis of SLE.

Notes: Activated neutrophils release NETs covered with $\alpha$-NE, $\alpha$-LF, $\alpha$-MPO, or $\alpha$-LL-37. Chromatin and associated compounds are hallmark antigens of the autoimmune response of patients with SLE. Decreased activity of DNase I combined with a general (anti-inflammatory) clearance deficiency leads to the accumulation of NETs covered with proinflammatory and cytotoxic intracellular constituents. Opsonization of NETs with autoantbodies comes with immune complex formation followed by inflammatory clearance by blood-borne phagocytes. This process causes inflammation and tissue damage, thus stimulating pDC to secrete IFN- $\alpha$ and IL-6, ultimately resulting in the socalled "IFN $\alpha$ signature" typical of SLE. The pro-inflammatory cytokines secreted by pDCs induce long-lived plasma cell formation and massive autoantibody production. Abbreviations: $\alpha-N E$, antibodies against neutrophil elastase; $\alpha-M P O$, antibodies against myeloperoxidase; $\alpha$-LF, antibodies against lactoferrin; NET, neutrophil extracellular trap; IFN- $\alpha$, interferon-alpha; IL-6, interleukin-6; pDC, plasmacytoid dendritic cells; SLE, systemic lupus erythematosus; NETosis, neutrophil extracellular trap formation; NETs, neutrophil extracellular traps; $М \Phi$ : macrophage.

Under healthy conditions, cellular remnants of cells undergoing apoptosis in the germinal centers (GCs) of secondary lymphoid organs are taken up and digested by tingible body macrophages without their activation as antigen-presenting cells. Since the number and size of tingible body macrophages are decreased in patients with SLE, the persistence of cellular debris might favor the binding of apoptotic cell-derived autoantigens by follicular dendritic cells (fDC) and the subsequent presentation of nuclear autoantigens to autoreactive $B$ cells, resulting in their survival, activation, and expansion. ${ }^{79}$

Moreover, it has been shown that the levels of CRP are atypically low in patients with SLE. CRP serves as bridging molecule between phagocytes and their prey and reduces the inflammatory potential of apoptotic corpses ${ }^{80}$ This may result from its recognition by autoreactive antibodies. The fact that several components of the complex and diverse interplay in apoptotic cell clearance are reportedly defective in SLE emphasizes the multifactorial genesis of this disease. Finally, failures in opsonization and consequently in the clearance of apoptotic and necrotic cells result in the accumulation of autoantigens challenging immunological tolerance and causing the fueling of inflammation.

\section{Autoantibodies as disease-driving factors}

In healthy individuals, central and peripheral tolerance checkpoints ensure the elimination of autoreactive $T$ and $\mathrm{B}$ cells, protecting the organism against the development of autoimmunity. However, in the case of SLE, B- and T-cell tolerance is challenged and subsequently lost. This may be a consequence of a failure of clonal deletion of autoreactive $\mathrm{T}$ or rescue of autoreactive B cells..$^{79,81-85}$ 
In healthy GCs, fDC present immune complexes to maturing and mutating B cells, and provide survival signals in the case of cognate interaction of the B cell with the antigen of the immune complexes. In the lymph nodes of several SLE patients, uncleared nuclear remnants accumulate, which bind to $\mathrm{fDC}$ and provide survival signals for autoreactive B cells that had been generated by chance during the process of somatic hypermutation. The improper exposure of nuclear autoantigens in this delicate location is consequently prone to break self-tolerance to nuclear autoantigens. Indeed, the germline variants of autoantibodies often do not display autoreactivity. ${ }^{86}$ It is important to note that fDC are not derived from bone marrow, do not ingest particulate antigens, and are neither related to myeloid nor to plasmacytoid DC.

$\mathrm{B}$ cells that are positively selected in the GC by either immune complexes (immune B cells) or by nuclear debris (autoimmune B cells) can receive long-term survival signals from autoreactive $\mathrm{CD}^{+} \mathrm{T}$ cells in the mantle zone of the lymphatic tissue. B cells subsequently differentiate into memory or plasma cells which produce autoreactive antibodies. As already mentioned, autoantibodies are able to recognize cytoplasmic and nuclear autoantigens derived from cellular remnants, thereby opsonizing circulating self-antigens and facilitating the formation of inflammatory immune complexes. Thus, the production of autoantibodies is an important and characteristic feature in the course of SLE that greatly contributes to its etiopathogenesis. In patients with SLE, autoantibodies undergo isotype switch from $\operatorname{IgM}$ to $\mathrm{IgG}$ and affinity maturation. ${ }^{87}$ Opsonization of self-antigens by autoantibodies of the IgG isotype leads to Fc $\gamma$ receptor-mediated inflammatory phagocytosis. However, autoantibodies of the IgM isotype may serve as an ameliorative factor in SLE, since they are discussed to opsonize autoantigens for an anti-inflammatory engulfment, thus avoiding the challenge of self-tolerance..$^{51,88,89}$

Importantly, the status of glycosylation of complexed IgG seems to have an impact on disease activity, since lectin binding to native complexed IgG is increased in patients with SLE. Immune complexes with highly fucosylated autoantibodies may be engulfed more efficiently by phagocytes and, thereby, foster inflammation. ${ }^{90}$ In contrast, the loss of terminal galactose in the Fc part of IgG results in increased complement activation ${ }^{91}$ favoring the clearance of dead cell remnants, and the absence of terminal sialic acid reportedly suppresses antibody-dependent cell-mediated cytotoxicity. ${ }^{92}$

\section{Dendritic cells and SLE}

DC are a heterogeneous group of cells with two major populations: myeloid DC (mDC) and pDC. DC are scattered over the entire body, where they serve as sentinels ( $\mathrm{mDC}$ and
$\mathrm{pDC}$ ) and scavengers (mDC) for pathogens. mDC finally process and present phagocytosed antigens to naïve $\mathrm{T}$ cells in an immune-stimulatory or tolerance inducing fashion. Note that fDC are a completely different cell type that is not human leukocyte antigen-restricted and not derived from bone marrow precursors. fDC present surface-bound antigens in immune complexes to follicular B cells.

DC need to mature from antigen-capturing toward antigen-presenting cells. During this process, they increase the surface expression of major histocompatibility complex as well as costimulatory molecules (CD80, CD86, and CD40). Maturation is also accompanied by the secretion of high levels of proinflammatory cytokines such as IL-12, IL-6, and TNF- $\alpha$, which enable DC to drive the type of T-cell polarization. ${ }^{93}$ Mature DC may present self-antigens to $\mathrm{T}$ cells leading to their differentiation into two subsets, $\mathrm{T}$ follicular helper and Th17 cells, and inhibit the development of regulatory $\mathrm{T}$ cells with tolerogenic capacity. ${ }^{94}$ Immature DC are crucial for the maintenance of epitope-specific tolerance, when they present antigen in the absence of costimulation to $\mathrm{T}$ cells leading to anergy or deletion of autoreactive $\mathrm{T}$ lymphocytes and development of regulatory T cells. ${ }^{95}$ In the context of SLE, mDC present modified macromolecules in an immunogenic manner and challenge the tolerance against nuclear autoantigens. DC employ pattern recognition receptors such as toll-like receptors (TLR) to recognize their targets. ${ }^{96} \mathrm{mDC}$ express most of the known TLR, whereas pDC only express TLR7 and TLR9 that recognize ssRNA and CpG DNA, respectively. ${ }^{97-99}$ Opsonization of autoantigens by autoantibodies leads to the activation of pDC, the natural IFN-producing cells. This results in elevated expression of IFN- $\alpha$-regulated genes in patients with SLE, referred to as "type-1 interferon signature". As a consequence, CD80 and CD86 are upregulated and serve as signals for survival and expansion of autoreactive $\mathrm{CD}^{+}$ helper $\mathrm{T}$ cells. The latter may support autoreactive B cells and $\mathrm{CD}^{+}$cytotoxic T cells. Upregulation of TLR7 by IFN- $\alpha$ leads to an enhanced response against immune complexes containing nucleic acids and in an elevated production of IFN- $\alpha$, thus fueling an inflammatory loop. ${ }^{100}$

\section{Therapeutic options}

In order to treat SLE, nonsteroidal anti-inflammatory drugs (NSAIDs) as well as immunosuppressive corticosteroids are commonly used. In the combination with these drugs, plasma exchange is used in patients with life-threatening manifestations to remove autoreactive antibodies and harmful immune complexes. ${ }^{101}$ These conventional therapies have limitations and are frequently accompanied by adverse side effects. As mentioned earlier, autoreactive IgG contributes to the immune 
pathology of SLE. IgG antibodies are required and sufficient to protect the organism against certain microbial infections. This dual role is referred to as intravenous IgG paradox. Thus, substitution of $\operatorname{IgG}$ levels by intravenous immunoglobulin preparations is an important treatment option for patients with SLE after plasma exchange. Intravenous immunoglobulin preparations consist of IgG from pooled serum of thousands of donors. ${ }^{102,103}$ Another therapeutic option for patients with refractory SLE is B-cell depletion by rituximab, a chimeric anti-CD20 antibody that temporarily depletes B cells as well as short-lived plasma cells. ${ }^{104}$ Belimumab, a monoclonal antibody that specifically targets the B lymphocyte stimulator and therefore disturbs B-cell activation, proliferation, and survival, has been approved to treat SLE. ${ }^{105}$ In few patients with refractory SLE with high uncontrolled disease activity, autologous bone marrow transplantation and inhibition of the proteasome with bortezomib may be employed as last option. ${ }^{106,107}$
In recent years, targeted therapies emerged as new potential therapeutic options, due to a better understanding of the etiopathogenesis of SLE. As discussed earlier, changes in the glycosylation pattern of IgG may either foster or ameliorate inflammatory diseases. Since it is known that deglycosylated IgG is unable to elicit antibody-dependent cell-mediated cytotoxicity and complement activation, one therapeutic option might be modulation of antibody glycosylation. ${ }^{108} \mathrm{~A}$ potent glycosylation modulator is endoglycosidase EndoS, which specifically cleaves the sugar moiety of the Fc portion of $\mathrm{IgG}^{102,109}$ making it a potential tool for SLE immunotherapy. Another promising target is the pathogenic loop of DC activation and IFN- $\alpha$ production, which precipitates the development of SLE. Monoclonal antibodies targeting type-I IFN ${ }^{110-112}$ or molecules inhibiting TLR signaling are promising agents interfering with the above-mentioned pathogenic cycle. The antimalarial drugs chloroquine and hydroxychloroquine dis-

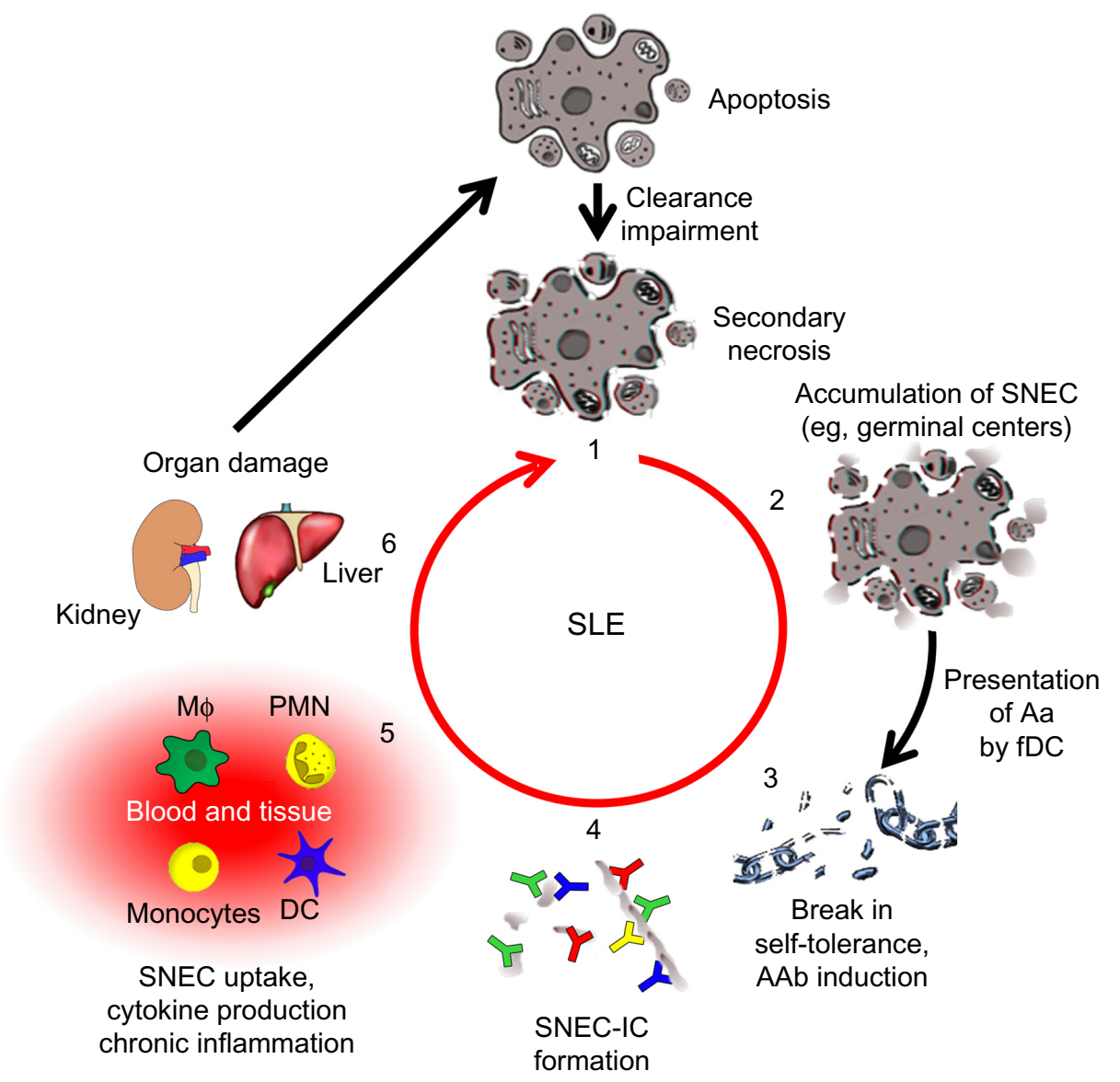

Figure 2 The vicious cycle of SLE.

Notes: A deficiency in the clearance of apoptotic cells leads to autoimmunity and chronic inflammation ( 1 ). When apoptotic cells fail to be cleared in time, they get secondary necrosis, leading to the accumulation of SNEC (2). Self-tolerance is broken when SNEC-derived autoantigens (Aag) are presented to autoreactive B cells by fDC. With help from autoreactive helper T cells, these B cells undergo affinity maturation and differentiate into memory B cells, thus establishing autoimmunity (3). IC are formed when autoantibodies (AAb) encounter SNEC in circulation or tissue (4). Newly formed SNEC-IC are then processed by blood-borne phagocytes and dendritic cells (DC) accompanied by the secretion of pro-inflammatory cytokines (5). This in turn leads to severe organ damage and cell death fueling the vicious cycle that maintains chronic inflammation (6).

Abbreviations: SNEC, secondary necrotic cell-derived material; fDC, follicular dendritic cells; IC, immune complex; SLE, systemic lupus erythematosus; DC, dendritic cells; MФ: macrophage, PMN: polymorphonuclear leukocytes. 
play antithrombotic and anti-lipidemic effects, prevent lupus flares, and increase the long-term survival of patients with SLE. ${ }^{113,114}$ Another putative target for therapeutic intervention is IL-6 which, inter alia, contributes to the maturation of B cells into plasma cells. Increased levels of this proinflammatory cytokine correlate with disease activity of patients with SLE. ${ }^{115}$ Tocilizumab, a monoclonal antibody targeting IL-6 receptor, is a promising agent that can effectively block IL-6 signaling. Moreover, autoreactive IgM came into focus, since it is considered to be an ameliorative factor in the course of SLE and may be used in antibody therapy. ${ }^{51,88,89}$ Nevertheless, additional studies are necessary to explore and exploit this therapeutic repertoire.

\section{Conclusion and future direction of research}

Despite the fact that the knowledge about the etiopathogenesis of SLE has increased in the past few years, there are still unanswered questions. It is well established that a deficiency of the fast and efficient removal of dead cell corpses and debris plays a central role in the course of the disease (Figure 2). Therefore, therapeutic intervention in the vicious cycle of SLE by rescuing the failure of dead cell clearance is a promising approach. Recent studies have given new insights into the course of SLE, providing new possibilities for the development of targeted therapeutic strategies. So far, secondary necrosis was thought to be the major source of autoantigens triggering autoimmunity. Recently, NETosis has come into focus as another form of cell death with similar effects. This raises the question of whether therapeutic targeting of neutrophils is a new treatment option.

The current treatment of SLE with NSAIDs or immunosuppressive drugs generally ameliorates disease manifestations. Nevertheless, the patient's life quality is affected. An important aspect is reaching a balance between inhibition of disease-inducing inflammation and maintenance of the beneficiary host immune response. The powerful tools, which are provided by research, may be exploited in combination with commonly used drugs in future therapeutic interventions. However, the possible side effects of these therapeutic agents, such as deglycosylated IgG or anti-inflammatory IgM antibodies as well as agents targeting DC and type-I IFN, have to be examined carefully. The complexity of the disease emphasizes the need of combined therapy specifically targeting the inflammatory loop driving the pathology of SLE.

\section{Disclosure}

The authors report no conflicts of interest in this work.

\section{References}

1. Munoz LE, Janko C, Schulze C, et al. Autoimmunity and chronic inflammation - two clearance-related steps in the etiopathogenesis of SLE. Autoimmun Rev. 2010;10(1):38-42.

2. Perniok A, Wedekind F, Herrmann M, Specker C, Schneider M. High levels of circulating early apoptic peripheral blood mononuclear cells in systemic lupus erythematosus. Lupus. 1998;7(2):113-118.

3. Rhodes B, Vyse TJ. The genetics of SLE: an update in the light of genome-wide association studies. Rheumatology (Oxford). 2008;47(11): 1603-1611.

4. Cooper GS, Miller FW, Pandey JP. The role of genetic factors in autoimmune disease: implications for environmental research. Environ Health Perspect. 1999;107(Suppl 5):693-700.

5. Edwards CJ. Environmental factors and lupus: are we looking too late? Lupus. 2005;14(6):423-425.

6. Pons-Estel GJ, Alarcon GS, Scofield L, Reinlib L, Cooper GS. Understanding the epidemiology and progression of systemic lupus erythematosus. Semin Arthritis Rheum. 2010;39(4):257-268.

7. Ippolito A, Wallace DJ, Gladman D, et al. Autoantibodies in systemic lupus erythematosus: comparison of historical and current assessment of seropositivity. Lupus. 2011;20(3):250-255.

8. Pradhan VD, Badakere SS, Bichile LS, Almeida AF. Anti-neutrophil cytoplasmic antibodies (ANCA) in systemic lupus erythematosus: prevalence, clinical associations and correlation with other autoantibodies. J Assoc Physicians India. 2004;52:533-537.

9. Bouts YM, Wolthuis DF, Dirkx MF, et al. Apoptosis and NET formation in the pathogenesis of SLE. Autoimmunity. 2012;45(8):597-601.

10. Munoz LE, Gaipl US, Franz S, et al. SLE - a disease of clearance deficiency? Rheumatology (Oxford). 2005;44(9):1101-1107.

11. Lu JH, Teh BK, Wang L, et al. The classical and regulatory functions of C1q in immunity and autoimmunity. Cell Mol Immunol. 2008;5(1): 9-21.

12. Miles K, Heaney J, Sibinska Z, et al. A tolerogenic role for Toll-like receptor 9 is revealed by B-cell interaction with DNA complexes expressed on apoptotic cells. Proc Natl Acad Sci U S A. 2012;109(3): 887-892.

13. Renehan AG, Bach SP, Potten CS. The relevance of apoptosis for cellular homeostasis and tumorigenesis in the intestine. Can J Gastroenterol. 2001;15(3):166-176.

14. Henson PM, Hume DA. Apoptotic cell removal in development and tissue homeostasis. TrendsImmunol. 2006;27(5):244-250.

15. Ravichandran KS, Lorenz U. Engulfment of apoptotic cells: signals for a good meal. Nat Rev Immunol. 2007;7(12):964-974.

16. Savill J. Apoptosis in resolution of inflammation. J Leukoc Biol. 1997; 61(4):375-380.

17. Liu X, Zou H, Slaughter C, Wang X. DFF, a heterodimeric protein that functions downstream of caspase-3 to trigger DNA fragmentation during apoptosis. Cell. 1997;89(2):175-184.

18. Sakahira H, Enari M, Nagata S. Cleavage of CAD inhibitor in CAD activation and DNA degradation during apoptosis. Nature. 1998;391(6662): 96-99.

19. Lazebnik YA, Kaufmann SH, Desnoyers S, Poirier GG, Earnshaw WC. Cleavage of poly(ADP-ribose) polymerase by a proteinase with properties like ICE. Nature. 1994;371(6495):346-347.

20. Gu Y, Sarnecki C, Aldape RA, Livingston DJ, Su MS. Cleavage of poly(ADP-ribose) polymerase by interleukin-1 beta converting enzyme and its homologs TX and Nedd-2. J Biol Chem. 1995;270(32): 18715-18718.

21. Chaurio RA, Munoz LE, Maueroder C, et al. The progression of cell death affects the rejection of allogeneic tumors in immune-competent mice - implications for cancer therapy. Front Immunol. 2014;5:560.

22. Parthasarathy G, Philipp MT. Review: apoptotic mechanisms in bacterial infections of the central nervous system. Front Immunol. 2012;3:306.

23. Bilyy RO, Shkandina T, Tomin A, et al. Macrophages discriminate glycosylation patterns of apoptotic cell-derived microparticles. J Biol Chem. 2012;287(1):496-503. 
24. Peter C, Wesselborg S, Herrmann M, Lauber K. Dangerous attraction: phagocyte recruitment and danger signals of apoptotic and necrotic cells. Apoptosis. 2010;15(9):1007-1028.

25. Voll RE, Herrmann M, Roth EA, Stach C, Kalden JR, Girkontaite I. Immunosuppressive effects of apoptotic cells. Nature. 1997;390(6658): 350-351.

26. Fadok VA, de Cathelineau A, Daleke DL, Henson PM, Bratton DL. Loss of phospholipid asymmetry and surface exposure of phosphatidylserine is required for phagocytosis of apoptotic cells by macrophages and fibroblasts. J Biol Chem. 2001;276(2):1071-1077.

27. Chaurio RA, Janko C, Munoz LE, Frey B, Herrmann M, Gaipl US. Phospholipids: key players in apoptosis and immune regulation. Molecules. 2009;14(12):4892-4914.

28. Williamson P, Schlegel RA. Transbilayer phospholipid movement and the clearance of apoptotic cells. Biochim Biophys Acta. 2002;1585(2-3): 53-63.

29. Dillon SR, Mancini M, Rosen A, Schlissel MS. Annexin V binds to viable B cells and colocalizes with a marker of lipid rafts upon B cell receptor activation. J Immunol. 2000;164(3):1322-1332.

30. Fischer K, Voelkl S, Berger J, Andreesen R, Pomorski T, Mackensen A. Antigen recognition induces phosphatidylserine exposure on the cell surface of human CD8+ T cells. Blood. 2006;108(13): 4094-4101.

31. Segawa K, Suzuki J, Nagata S. Constitutive exposure of phosphatidylserine on viable cells. Proc Natl Acad Sci U S A. 2011;108(48): 19246-19251.

32. Janko C, Jeremic I, Biermann M, et al. Cooperative binding of Annexin A5 to phosphatidylserine on apoptotic cell membranes. Phys Biol. 2013;10(6):065006.

33. Biermann M, Maueroder C, Brauner JM, et al. Surface code biophysical signals for apoptotic cell clearance. Phys Biol. 2013;10(6): 065007.

34. Gregory CD, Pound JD. Cell death in the neighbourhood: direct microenvironmental effects of apoptosis in normal and neoplastic tissues. J Pathol. 2011;223(2):177-194.

35. Kim S, Park SY, Kim SY, et al. Cross talk between engulfment receptors stabilin-2 and integrin alphavbeta5 orchestrates engulfment of phosphatidylserine-exposed erythrocytes. Mol Cell Biol. 2012;32(14) 2698-2708.

36. Kobayashi N, Karisola P, Pena-Cruz V, et al. TIM-1 and TIM-4 glycoproteins bind phosphatidylserine and mediate uptake of apoptotic cells. Immunity. 2007;27(6):927-940.

37. Ishimoto Y, Ohashi K, Mizuno K, Nakano T. Promotion of the uptake of PS liposomes and apoptotic cells by a product of growth arrest-specific gene, gas6. J Biochem. 2000;127(3):411-417.

38. Kruse K, Janko C, Urbonaviciute V, et al. Inefficient clearance of dying cells in patients with SLE: anti-dsDNA autoantibodies, MFG-E8, HMGB-1 and other players. Apoptosis. 2010;15(9):1098-1113.

39. Kinchen JM, Ravichandran KS. Journey to the grave: signaling events regulating removal of apoptotic cells. J Cell Sci. 2007;120(Pt 13): 2143-2149.

40. Bournazou I, Pound JD, Duffin R, et al. Apoptotic human cells inhibit migration of granulocytes via release of lactoferrin. J Clin Invest. 2009; 119(1):20-32.

41. Vermes I, Haanen C, Richel DJ, Schaafsma MR, Kalsbeek-Batenburg E, Reutelingsperger CP. Apoptosis and secondary necrosis of lymphocytes in culture. Acta Haematol. 1997;98(1):8-13.

42. Wu X, Molinaro C, Johnson N, Casiano CA. Secondary necrosis is a source of proteolytically modified forms of specific intracellular autoantigens: implications for systemic autoimmunity. Arthritis Rheum. 2001;44(11):2642-2652.

43. Kono H, Rock KL. How dying cells alert the immune system to danger. Nat Rev Immunol. 2008;8(4):279-289.

44. Urbonaviciute V, Furnrohr BG, Meister S, et al. Induction of inflammatory and immune responses by HMGB1-nucleosome complexes: implications for the pathogenesis of SLE. J Exp Med. 2008;205(13): 3007-3018.
45. Munoz LE, Janko C, Grossmayer GE, et al. Remnants of secondarily necrotic cells fuel inflammation in systemic lupus erythematosus. Arthritis Rheum. 2009;60(6):1733-1742.

46. Munoz LE, Lauber K, Schiller M, Manfredi AA, Herrmann M. The role of defective clearance of apoptotic cells in systemic autoimmunity. Nat Rev Rheumatol. 2010;6(5):280-289.

47. Gaipl US, Beyer TD, Baumann I, et al. Exposure of anionic phospholipids serves as anti-inflammatory and immunosuppressive signal implications for antiphospholipid syndrome and systemic lupus erythematosus. Immunobiology. 2003;207(1):73-81.

48. Rekvig OP, Mortensen ES. Immunity and autoimmunity to dsDNA and chromatin - the role of immunogenic DNA-binding proteins and nuclease deficiencies. Autoimmunity. 2012;45(8):588-592.

49. Gaipl US, Beyer TD, Heyder P, et al. Cooperation between C1q and DNase I in the clearance of necrotic cell-derived chromatin. Arthritis Rheum. 2004;50(2):640-649.

50. Kerr JF, Wyllie AH, Currie AR. Apoptosis: a basic biological phenomenon with wide-ranging implications in tissue kinetics. Br J Cancer. 1972;26(4):239-257.

51. Biermann MH, Veissi S, Maueroder C, et al. The role of dead cell clearance in the etiology and pathogenesis of systemic lupus erythematosus: dendritic cells as potential targets. Expert Rev Clin Immunol. 2014; 10(9):1151-1164.

52. Witko-Sarsat V, Rieu P, Descamps-Latscha B, Lesavre P, HalbwachsMecarelli L. Neutrophils: molecules, functions and pathophysiological aspects. Lab Invest. 2000;80(5):617-653.

53. Scapini P, Laudanna C, Pinardi C, et al. Neutrophils produce biologically active macrophage inflammatory protein-3alpha (MIP3alpha)/CCL20 and MIP-3beta/CCL19. Eur J Immunol. 2001;31(7): 1981-1988.

54. Iba T, Hashiguchi N, Nagaoka I, Tabe Y, Murai M. Neutrophil cell death in response to infection and its relation to coagulation. J Intens Care. 2013;1(1):13.

55. Brinkmann V, Reichard U, Goosmann C, et al. Neutrophil extracellular traps kill bacteria. Science. 2004;303(5663):1532-1535.

56. Schorn C, Janko C, Latzko M, Chaurio R, Schett G, Herrmann M. Monosodium urate crystals induce extracellular DNA traps in neutrophils, eosinophils, and basophils but not in mononuclear cells. Front Immunol. 2012;3:277.

57. Papayannopoulos V, Metzler KD, Hakkim A, Zychlinsky A. Neutrophil elastase and myeloperoxidase regulate the formation of neutrophil extracellular traps. J Cell Biol. 2010;191(3):677-691.

58. Metzler KD, Fuchs TA, NauseefWM, et al. Myeloperoxidase is required for neutrophil extracellular trap formation: implications for innate immunity. Blood. 2011;117(3):953-959.

59. Nakashima K, Hagiwara T, Ishigami A, et al. Molecular characterization of peptidylarginine deiminase in HL-60 cells induced by retinoic acid and 1alpha,25-dihydroxyvitamin D(3). J Biol Chem. 1999;274(39): 27786-27792.

60. Nakashima K, Hagiwara T, Yamada M. Nuclear localization of peptidylarginine deiminase $\mathrm{V}$ and histone deimination in granulocytes. J Biol Chem. 2002;277(51):49562-49568.

61. Vossenaar ER, Zendman AJ, van Venrooij WJ, Pruijn GJ. PAD, a growing family of citrullinating enzymes: genes, features and involvement in disease. Bioessays. 2003;25(11):1106-1118.

62. Fuchs TA, Abed U, Goosmann C, et al. Novel cell death program leads to neutrophil extracellular traps. J Cell Biol. 2007;176(2):231-241.

63. Pieterse E, van der Vlag J. Breaking immunological tolerance in systemic lupus erythematosus. Front Immunol. 2014;5:164.

64. Miller BF, Abrams R, Dorfman A, Klein M. Antibacterial properties of protamine and histone. Science. 1942;96(2497):428-430.

65. Hoffmann MH, Bruns H, Backdahl L, et al. The cathelicidins LL-37 and rCRAMP are associated with pathogenic events of arthritis in humans and rats. Ann Rheum Dis. 2013;72(7):1239-1248

66. Lande R, Ganguly D, Facchinetti V, et al. Neutrophils activate plasmacytoid dendritic cells by releasing self-DNA-peptide complexes in systemic lupus erythematosus. Sci Transl Med. 2011;3(73):73ra19. 
67. Garcia-Romo GS, Caielli S, Vega B, et al. Netting neutrophils are major inducers of type I IFN production in pediatric systemic lupus erythematosus. Sci Transl Med. 2011;3(73):73ra20.

68. Urbonaviciute V, Voll RE. High-mobility group box 1 represents a potential marker of disease activity and novel therapeutic target in systemic lupus erythematosus. $J$ Int Med. 2011;270(4):309-318.

69. Hakkim A, Furnrohr BG, Amann K, et al. Impairment of neutrophil extracellular trap degradation is associated with lupus nephritis. Proc Natl Acad Sci U S A. 2010;107(21):9813-9818.

70. Coit $\mathrm{P}$, Yalavarthi $\mathrm{S}$, Ognenovski $\mathrm{M}$, et al. Epigenome profiling reveals significant DNA demethylation of interferon signature genes in lupus neutrophils. J Autoimmun. 2015;58:59-66.

71. Schauer C, Janko C, Munoz LE, et al. Aggregated neutrophil extracellular traps limit inflammation by degrading cytokines and chemokines. Nat Med. 2014;20(5):511-517.

72. Ip WK, Chan SY, Lau CS, Lau YL. Association of systemic lupus erythematosus with promoter polymorphisms of the mannose-binding lectin gene. Arthritis Rheum. 1998;41(9):1663-1668.

73. Ricklin D, Hajishengallis G, Yang K, Lambris JD. Complement: a key system for immune surveillance and homeostasis. Nat Immunol. 2010;11(9):785-797.

74. Jog NR, Frisoni L, Shi Q, et al. Caspase-activated DNase is required for maintenance of tolerance to lupus nuclear autoantigens. Arthritis Rheum. 2012;64(4):1247-1256.

75. Herrmann M, Voll RE, Zoller OM, Hagenhofer M, Ponner BB, Kalden JR. Impaired phagocytosis of apoptotic cell material by monocyte-derived macrophages from patients with systemic lupus erythematosus. Arthritis Rheum. 1998;41(7):1241-1250.

76. Munoz LE, Chaurio RA, Gaipl US, Schett G, Kern P. MoMa from patients with systemic lupus erythematosus show altered adhesive activity. Autoimmunity. 2009;42(4):269-271.

77. Cairns AP, Crockard AD, McConnell JR, Courtney PA, Bell AL. Reduced expression of CD44 on monocytes and neutrophils in systemic lupus erythematosus: relations with apoptotic neutrophils and disease activity. Ann Rheum Dis. 2001;60(10):950-955.

78. Gaipl US, Munoz LE, Grossmayer G, et al. Clearance deficiency and systemic lupus erythematosus (SLE). J Autoimmun. 2007;28(2-3): 114-121.

79. Baumann I, Kolowos W, Voll RE, et al. Impaired uptake of apoptotic cells into tingible body macrophages in germinal centers of patients with systemic lupus erythematosus. Arthritis Rheum. 2002;46(1):191-201.

80. Kravitz MS, Shoenfeld Y. Autoimmunity to protective molecules: is it the perpetuum mobile (vicious cycle) of autoimmune rheumatic diseases? Nat Clin Prac Rheumatol. 2006;2(9):481-490.

81. Voll RE, Roth EA, Girkontaite I, et al. Histone-specific Th0 and Th1 clones derived from systemic lupus erythematosus patients induce double-stranded DNA antibody production. Arthritis Rheum. 1997; 40(12):2162-2171.

82. Theocharis S, Sfikakis PP, Lipnick RN, Klipple GL, Steinberg AD, Tsokos GC. Characterization of in vivo mutated $\mathrm{T}$ cell clones from patients with systemic lupus erythematosus. Clin Immunol Immunopathol. 1995;74(2):135-142.

83. Shivakumar S, Tsokos GC, Datta SK. T cell receptor alpha/beta expressing double-negative (CD4-/CD8-) and CD4+ Thelper cells in humans augment the production of pathogenic anti-DNA autoantibodies associated with lupus nephritis. J Immunol. 1989;143(1):103-112.

84. Camacho SA, Kosco-Vilbois MH, Berek C. The dynamic structure of the germinal center. Immunol Today. 1998;19(11):511-514.

85. Mevorach D, Mascarenhas JO, Gershov D, Elkon KB. Complementdependent clearance of apoptotic cells by human macrophages. $J$ Exp Med. 1998;188(12):2313-2320.

86. Schroeder K, Herrmann M, Winkler TH. The role of somatic hypermutation in the generation of pathogenic antibodies in SLE. Autoimmunity. 2013;46(2):121-127.

87. Winkler TH, Fehr H, Kalden JR. Analysis of immunoglobulin variable region genes from human IgG anti-DNA hybridomas. Eur J Immunol. 1992;22(7):1719-1728.
88. Saiki O, Saeki Y, Tanaka T, et al. Development of selective IgM deficiency in systemic lupus erythematosus patients with disease of long duration. Arthritis Rheum. 1987;30(11):1289-1292.

89. Witte T. IgM antibodies against dsDNA in SLE. Clin Rev Allergy Immunol. 2008;34(3):345-347.

90. Sjowall C, Zapf J, von Lohneysen S, et al. Altered glycosylation of complexed native $\mathrm{IgG}$ molecules is associated with disease activity of systemic lupus erythematosus. Lupus. 2014;24(6):569-581.

91. Malhotra R, Wormald MR, Rudd PM, Fischer PB, Dwek RA, Sim RB. Glycosylation changes of $\operatorname{IgG}$ associated with rheumatoid arthritis can activate complement via the mannose-binding protein. Nat Med. 1995;1(3):237-243.

92. Kaneko Y, Nimmerjahn F, Ravetch JV. Anti-inflammatory activity of immunoglobulin G resulting from Fc sialylation. Science. 2006;313(5787):670-673.

93. Blanco P, Palucka AK, Pascual V, Banchereau J. Dendritic cells and cytokines in human inflammatory and autoimmune diseases. Cytokine Growth Factor Rev. 2008;19(1):41-52.

94. Liao J, Chang C, Wu H, Lu Q. Cell-based therapies for systemic lupus erythematosus. Autoimmun Rev. 2015;14(1):43-48.

95. Banchereau J, Steinman RM. Dendritic cells and the control of immunity. Nature. 1998;392(6673):245-252.

96. Fransen JH, van der Vlag J, Ruben J, Adema GJ, Berden JH, Hilbrands LB. The role of dendritic cells in the pathogenesis of systemic lupus erythematosus. Arthritis Res Ther. 2010;12(2):207.

97. Seitz HM, Matsushima GK. Dendritic cells in systemic lupus erythematosus. Int Rev Immunol. 2010;29(2):184-209.

98. Diebold SS, Kaisho T, Hemmi H, Akira S, Reis e Sousa C. Innate antiviral responses by means of TLR7-mediated recognition of singlestranded RNA. Science. 2004;303(5663):1529-1531.

99. Ahmad-Nejad P, Hacker H, Rutz M, Bauer S, Vabulas RM, Wagner H. Bacterial CpG-DNA and lipopolysaccharides activate Toll-like receptors at distinct cellular compartments. Eur J Immunol. 2002;32(7): 1958-1968.

100. Ganguly D, Chamilos G, Lande R, et al. Self-RNA-antimicrobial peptide complexes activate human dendritic cells through TLR7 and TLR8. J Exp Med. 2009;206(9):1983-1994.

101. Pagnoux C. Plasma exchange for systemic lupus erythematosus. Transfus Aphere Sci. 2007;36(2):187-193.

102. Allhorn M, Olin AI, Nimmerjahn F, Collin M. Human IgG/Fc gamma $\mathrm{R}$ interactions are modulated by streptococcal IgG glycan hydrolysis. PloS One. 2008;3(1):e1413.

103. Nimmerjahn F, Ravetch JV. The antiinflammatory activity of IgG: the intravenous IgG paradox. $J$ Exp Medicine. 2007;204(1):11-15.

104. Ng KP, Leandro MJ, Edwards JC, Ehrenstein MR, Cambridge G, Isenberg DA. Repeated B cell depletion in treatment of refractory systemic lupus erythematosus. Ann Rheum Dis. 2006;65(7): 942-945.

105. Lutalo PM, D'Cruz DP. Update on belimumab for the management of systemic lupus erythematosus. Expert Opin Biol Ther. 2014;14(11): 1701-1708.

106. Neubert K, Meister S, Moser K, et al. The proteasome inhibitor bortezomib depletes plasma cells and protects mice with lupus-like disease from nephritis. Nat Med. 2008;14(7):748-755.

107. Illei GG, Cervera R, Burt RK, et al. Current state and future directions of autologous hematopoietic stem cell transplantation in systemic lupus erythematosus. Ann Rheum Dis. 2011;70(12):2071-2074.

108. Nose M, Wigzell H. Biological significance of carbohydrate chains on monoclonal antibodies. Proc Natl Acad Sci U S A. 1983;80(21): 6632-6636.

109. Collin M, Olsen A. EndoS, a novel secreted protein from Streptococcus pyogenes with endoglycosidase activity on human IgG. EMBO J. 2001;20(12):3046-3055.

110. Merrill JT, Wallace DJ, Petri M, et al. Safety profile and clinical activity of sifalimumab, a fully human anti-interferon alpha monoclonal antibody, in systemic lupus erythematosus: a phase I, multicentre, doubleblind randomised study. Ann Rheum Dis. 2011;70(11):1905-1913. 
111. McBride JM, Jiang J, Abbas AR, et al. Safety and pharmacodynamics of rontalizumab in patients with systemic lupus erythematosus: results of a phase I, placebo-controlled, double-blind, dose-escalation study. Arthritis Rheum. 2012;64(11):3666-3676.

112. Lauwerys BR, Hachulla E, Spertini F, et al. Down-regulation of interferon signature in systemic lupus erythematosus patients by active immunization with interferon alpha-kinoid. Arthritis Rheum. 2013;65(2):447-456.

113. Wallace DJ, Gudsoorkar VS, Weisman MH, Venuturupalli SR. New insights into mechanisms of therapeutic effects of antimalarial agents in SLE. Nat Rev Rheumatol. 2012;8(9):522-533.
114. Ruiz-Irastorza G, Ramos-Casals M, Brito-Zeron P, Khamashta MA. Clinical efficacy and side effects of antimalarials in systemic lupus erythematosus: a systematic review. Ann Rheum Dis. 2010;69(1):20-28.

115. Linker-Israeli M, Deans RJ, Wallace DJ, Prehn J, Ozeri-Chen T, Klinenberg JR. Elevated levels of endogenous IL-6 in systemic lupus erythematosus. A putative role in pathogenesis. J Immunol. 1991; 147(1):117-123.

Journal of Inflammation Research

\section{Publish your work in this journal}

The Journal of Inflammation Research is an international, peer-reviewed open-access journal that welcomes laboratory and clinical findings on the molecular basis, cell biology and pharmacology of inflammation including original research, reviews, symposium reports, hypothesis formation and commentaries on: acute/chronic inflammation; mediators of inflamma-

\section{Dovepress}

tion; cellular processes; molecular mechanisms; pharmacology and novel anti-inflammatory drugs; clinical conditions involving inflammation. The manuscript management system is completely online and includes a very quick and fair peer-review system. Visit http://www.dovepress.com/ testimonials.php to read real quotes from published authors.

Submit your manuscript here: http://www.dovepress.com/journal-of-inflammation-research-journal 